\title{
Targeted deletion of Nmnatı in mouse retina leads to early severe retinal dystrophy
}

Xiaolin Wang ${ }^{1}$, Yu Fang ${ }^{2}$, Rongsheng Liao ${ }^{1}$, Tao Wang ${ }^{1,2,3}$

1 Department of Pathology, Sichuan Medical College, Chengdu, Sichuan, China 610065

2 Department of Neuroscience, Sichuan Medical College, Chengdu, Sichuan, China 610065

3 Department of Molecular Biology, Sichuan Medical College, Chengdu, Sichuan, China 610065

\section{CORRESPONDENCE}

Tao Wang

Department of Pathology, Sichuan Medical College

Chengdu, Sichuan, China 610065 


\begin{abstract}
Mutations in NMNAT1 can lead to a very severe type of retinal dystrophy, Leber congenital amaurosis, in human patients, characterized by infantile-onset or congenital retinal dystrophy and childhood blindness. The loss-of-function mouse models of Nmnat1 have not been well-established, since the complete knock-out (KO) of Nmnatı in mice results in embryonic lethality. Here, we generated retina-specific KO by using the Crxpromotor-driving Cre combined with the flox allele. By a panel of histological and functional analyses, we found that Nmnatı conditional $\mathrm{KO}(\mathrm{cKO})$ mice have early severe retinal dystrophy. Specifically, the photoreceptors of Nmnatı cKO mice are almost diminished and the retinal functions also become completely abolished. Our results established a loss-of-function model for Nmnatı in mice, which will be useful for studying the detailed functions of NMNAT1 in the retina.
\end{abstract}




\section{INTRODUCTION}

Leber congenital amaurosis (LCA) is a severe inherited eye disease characterized by infantile-onset visual impairment and vision loss $(1,2)$. Though LCA is a rare disease with an incidence about only 1 in 80000 (3), it is the most common cause of incurable children blindness (10\%-18\%) (1). LCA is a highly genetically heterogeneous disease. During the past 20 years, various genetic analyses have identified at least 19 genes that cause LCA(427). However, the mutations in these genes account for approximately $70 \%$ of all LCA cases, leaving $20 \%-30 \%$ unsolved cases to be discovered for their genetic basis (28).

Sequencing studies have recently found that mutations in NMNAT1 can cause LCA and these constitute approximately $10 \%$ of unsolved cases $(28-47)$. The majority of NMNAT1 mutations found in LCA patients are missense, with a small portion are nonsense and frameshift. Most of the patients share a variant (c.769G>A, E257K), while the other allele is heterogeneous spreading from $\mathrm{N}$-terminal to C-terminal (30). In silico analysis predicts that these mutations will affect the enzymatic activity, hexamerization, hydrophobic interactions or nuclear localization of NMNAT1 protein (31).

Though one mouse model with Nmnatı homozygous missense mutation was reported recently (48), it remains unknown what is the impact of retina-specific deletion of 
Nmnatı in mice. Therefore, in this study, we generated retina-specific knock-out Nmnatı mice and found that this genetic defect can lead to early severe retinal dystrophy.

\section{METHODS}

\section{Mouse study}

Nmnatı retina-specific KO mice were generated by crossing the Nmnat ${ }^{\text {flox/flox }}$ mice with Crx-Cre ${ }^{+/-}$mice to get the Nmnati ${ }^{\text {flox } /+} ; \mathrm{Crx}_{-} \mathrm{Cre}^{+/-}$mice. Then these mice underwent further mating to get the Nmnatı retina-specific KO mice. The mouse study protocols were approved by the Institutional Review Board of Sichuan Medical College.

\section{Histological study}

For histological studies of the mouse retina, the mice were sacrificed and the eyecups were enucleated and fixed. The eyecups were embedded in paraffin and then sectioned to $10 \mu \mathrm{m}$ slices. The sections underwent Hematoxylin and Eosin (HE) staining after rehydration. The number of nuclear layers were counted as the indicator of retinal thickness.

\section{Electroretinogram (ERG)}


As for the ERG experiments, the mice underwent dark adaptation for overnight (at least 10 hours) before the experiments, and the ERGs are recorded in the dark with dim red lights. Mice were anesthetized with Ketamine and then put in the chambers for the actual testing. The heads of the mice were stabilized properly. Six different light stimuli amplitudes were applied and the retinal responses were recorded by the electrodes attached to the cornea of the mice. The responses contain a-wave and b-wave responses. Then the data were analyzed and plotted according to their genotypes.

\section{RESULTS}

At the age of $\mathrm{P}_{7}$, since the outer nuclear layer (ONL) and inner nuclear layer (INL) have not been fully developed and separated, we used the thickness of the two layers as the indicator. By H\&E staining, we found that the ONL and INL thickness in those cKO mice is only about $45 \%$ compared with that in WT mice. The thickness of ganglion cell layer (GCL) is a little bit smaller in cKO mice compared with WT (Figure 1A).

When the mice grow to $\mathrm{P} 14$, the retinal layer thinning becomes more remarkable in cKO mice compared with WT mice. Both the ONL and INL show apparent dystrophy in cKO mice. Similar to $\mathrm{P}_{7}$, the GCL is about $20 \%$ thinner in cKO mice (Figure $1 \mathrm{~B}$ ). 
At the age of $\mathrm{P} 28$, the ONL (photoreceptor layer) becomes almost diminished in cKO mice, and the INL is also severely dystrophic in cKO. The GCL does not show apparent dystrophy in cKO, similar to $\mathrm{P}_{7}$ and $\mathrm{P}_{14}$ (Figure ${ }_{1} \mathrm{C}$ ).

As for the functional analysis, we used ERG to measure the retinal electric responses to the light stimuli. At the age of $\mathrm{P}_{2} 8$, ERG experiments revealed that the cKO mice do not have any a-wave and b-wave responses to light compared with WT mice. (Figure $1 \mathrm{D}$ and

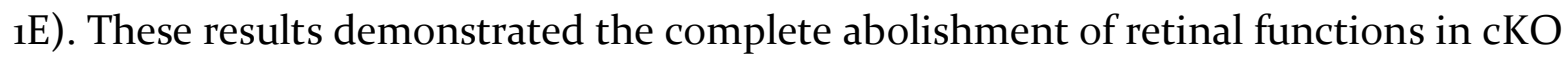
mice upon NMNAT1 deficiency.

\section{DISCUSSION}

Previous studies on axon protection indicated that NAD+ biosynthesis activity is essential for NMNAT1's role in protecting axons from degeneration (49-57). NAD+ is a fundamental molecule for the living organisms. It is a coenzyme involved in various cellular processes. NAD/NADH redox pair is essential for electric transfer chain and is utilized for the maintenance of cellular redox state (58). The axon protection conferred by NMNAT1 seems to be closely related to mitochondria, which is a critical organelle for the maintenance of redox state $(59,60)$. In addition, NMNAT1 also has other functional implications $(50,59,61-78)$. 
Interestingly, most of the LCA patients with NMNAT1 mutations show specific degeneration in the macula where the redox homeostasis is particularly important due to high oxygen consumption conferred by high density of photoreceptors $(30,79-83)$. This evidence, with the NAD+ function described early, provides a strong linkage between the need for $\mathrm{NAD}^{+}$biosynthesis and the maintenance of photoreceptor normal function.

Nmnatı complete knockout mice have been generated but they are embryonically lethal (66). Therefore, for studying the function of NMNAT1 in retina, conditional KO mice specifically targeting photoreceptors (NMNAT1 flox/flox; Crx-Cre+/-) were generated by us. Our results show that Nmnat1-cKO mice show extremely rapid photoreceptor loss and blindness. The phenotypes are somewhat consistent with some human LCA patients who were blind at very early stages, thus presenting a useful model for NMNAT1 functional study in the retina in the future.

\section{ACKNOWLEDGEMENTS}

This work was supported by Sichuan Province Nature Science Funding (No.3160o642). We thank Dr. Fei Luo for the help on study design. 


\section{REFERENCES}

1. den Hollander Al, Roepman R, Koenekoop RK, Cremers FP. Leber congenital amaurosis: genes, proteins and disease mechanisms. Progress in retinal and eye research. 2008;27(4):391-419.

2. Weleber RG, Francis PJ, Trzupek KM, Beattie C. Leber Congenital Amaurosis. In: Adam MP, Ardinger HH, Pagon RA, Wallace SE, Bean LJH, Mefford HC, et al., editors. GeneReviews(R). Seattle (WA): University of Washington, Seattle University of Washington, Seattle. GeneReviews is a registered trademark of the University of Washington, Seattle. All rights reserved.; 1993.

3. Stone EM. Leber congenital amaurosis - a model for efficient genetic testing of heterogeneous disorders: LXIV Edward Jackson Memorial Lecture. American journal of ophthalmology. 2007;144(6):791-811.

4. den Hollander Al, ten Brink JB, de Kok YJ, van Soest S, van den Born LI, van Driel MA, et al. Mutations in a human homologue of Drosophila crumbs cause retinitis pigmentosa (RP12). Nature genetics. 1999;23(2):217-21.

5. Francis PJ. Genetics of inherited retinal disease. Journal of the Royal Society of Medicine. 2006;99(4):189-91. 
6. Bujakowska KM, Zhang Q, Siemiatkowska AM, Liu Q, Place E, Falk MJ, et al.

Mutations in IFT172 cause isolated retinal degeneration and Bardet-Biedl syndrome.

Human molecular genetics. 2015;24(1):230-42.

7. El-Asrag ME, Sergouniotis PI, McKibbin M, Plagnol V, Sheridan E, Waseem N, et al. Biallelic mutations in the autophagy regulator DRAM2 cause retinal dystrophy with early macular involvement. American journal of human genetics. 2015;96(6):948-54.

8. Saksens NT, Krebs MP, Schoenmaker-Koller FE, Hicks W, Yu M, Shi L, et al. Mutations in CTNNA1 cause butterfly-shaped pigment dystrophy and perturbed retinal pigment epithelium integrity. Nature genetics. 2016;48(2):144-51.

9. Vincent A, Audo I, Tavares E, Maynes JT, Tumber A, Wright T, et al. Biallelic Mutations in GNB3 Cause a Unique Form of Autosomal-Recessive Congenital Stationary Night Blindness. American journal of human genetics. 2016;98(5):1011-9.

10. Wang F, Li H, Xu M, Li H, Zhao L, Yang L, et al. A homozygous missense mutation in NEUROD1 is associated with nonsyndromic autosomal recessive retinitis pigmentosa. Investigative ophthalmology \& visual science. 2014;56(1):150-5.

11. Wang F, Wang Y, Zhang B, Zhao L, Lyubasyuk V, Wang K, et al. A missense mutation in HK1 leads to autosomal dominant retinitis pigmentosa. Investigative ophthalmology \& visual science. 2014;55(11):7159-64.

12. Salvo J, Lyubasyuk V, Xu M, Wang H, Wang F, Nguyen D, et al. Next-generation sequencing and novel variant determination in a cohort of 92 familial exudative 
vitreoretinopathy patients. Investigative ophthalmology \& visual science. 2015;56(3):1937-46.

13. Xu M, Gelowani V, Eblimit A, Wang F, Young MP, Sawyer BL, et al. ATF6 Is Mutated in Early Onset Photoreceptor Degeneration With Macular Involvement. Investigative ophthalmology \& visual science. 2015;56(6):3889-95.

14. Xu M, Yang L, Wang F, Li H, Wang X, Wang W, et al. Mutations in human IFT140 cause non-syndromic retinal degeneration. Human genetics. 2015;134(10):1069-78.

15. Arno G, Agrawal SA, Eblimit A, Bellingham J, Xu M, Wang F, et al. Mutations in REEP6 Cause Autosomal-Recessive Retinitis Pigmentosa. American journal of human genetics. 2016;99(6):1305-15.

16. Jonsson F, Burstedt MS, Sandgren O, Norberg A, Golovleva I. Novel mutations in CRB1 and ABCA4 genes cause Leber congenital amaurosis and Stargardt disease in a Swedish family. European journal of human genetics : EJHG. 2013;21(11):1266-71.

17. McAnany JJ, Genead MA, Walia S, Drack AV, Stone EM, Koenekoop RK, et al. Visual acuity changes in patients with leber congenital amaurosis and mutations in CEP290. JAMA ophthalmology. 2013;131(2):178-82.

18. Roman AJ, Cideciyan AV, Schwartz SB, Olivares MB, Heon E, Jacobson SG. Intervisit variability of visual parameters in Leber congenital amaurosis caused by RPE65 mutations. Investigative ophthalmology \& visual science. 2013;54(2):1378-83. 
19. Boye SE. Leber congenital amaurosis caused by mutations in GUCY2D. Cold Spring Harbor perspectives in medicine. 2014;5(1):a017350.

20. Corton M, Avila-Fernandez A, Vallespin E, Lopez-Molina MI, Almoguera B, Martin-

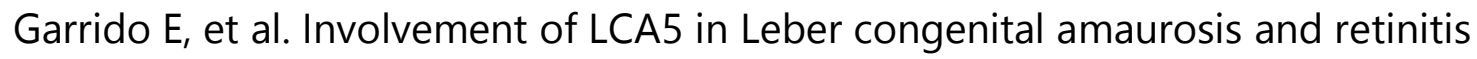
pigmentosa in the Spanish population. Ophthalmology. 2014;121(1):399-407.

21. Li T. Leber congenital amaurosis caused by mutations in RPGRIP1. Cold Spring Harbor perspectives in medicine. 2014;5(4).

22. Mo G, Ding Q, Chen Z, Li Y, Yan M, Bu L, et al. A novel mutation in the RPE65 gene causing Leber congenital amaurosis and its transcriptional expression in vitro. PloS one. 2014;9(11):e112400.

23. Hidalgo-de-Quintana J, Schwarz N, Meschede IP, Stern-Schneider G, Powner MB, Morrison EE, et al. The Leber congenital amaurosis protein AIPL1 and EB proteins Colocalize at the photoreceptor cilium. PloS one. 2015;10(3):e0121440.

24. Abouzeid H, Othman IS, Schorderet DF. A Novel Recessive RPGRIP1 Mutation Causing Leber Congenital Amaurosis. Klinische Monatsblatter fur Augenheilkunde. $2016 ; 233(4): 456-9$.

25. Kunde-Ramamoorthy G, Coarfa C, Laritsky E, Kessler NJ, Harris RA, Xu M, et al. Comparison and quantitative verification of mapping algorithms for whole-genome bisulfite sequencing. Nucleic acids research. 2014;42(6):e43. 
26. Wu Y, Fu X, Zhu X, He X, Zou C, Han Y, et al. Prognostic role of systemic inflammatory response in renal cell carcinoma: a systematic review and meta-analysis. Journal of cancer research and clinical oncology. 2011;137(5):887-96.

27. Zhang Q, Qi S, Xu M, Yu L, Tao Y, Deng Z, et al. Structure-function analysis reveals a novel mechanism for regulation of histone demethylase LSD2/AOF1/KDM1b. Cell research. 2013;23(2):225-41.

28. Chiang PW, Wang J, Chen Y, Fu Q, Zhong J, Chen Y, et al. Exome sequencing identifies NMNAT1 mutations as a cause of Leber congenital amaurosis. Nature genetics. 2012;44(9):972-4.

29. Falk MJ, Zhang Q, Nakamaru-Ogiso E, Kannabiran C, Fonseca-Kelly Z, Chakarova C, et al. NMNAT1 mutations cause Leber congenital amaurosis. Nature genetics. 2012;44(9):1040-5.

30. Koenekoop RK, Wang H, Majewski J, Wang X, Lopez I, Ren H, et al. Mutations in NMNAT1 cause Leber congenital amaurosis and identify a new disease pathway for retinal degeneration. Nature genetics. 2012;44(9):1035-9.

31. Perrault I, Hanein S, Zanlonghi X, Serre V, Nicouleau M, Defoort-Delhemmes S, et al. Mutations in NMNAT1 cause Leber congenital amaurosis with early-onset severe macular and optic atrophy. Nature genetics. 2012;44(9):975-7. 
32. Koenekoop RK, Wang H, Majewski J, Wang X, Lopez I, Ren H, et al. Mutations in NMNAT1 cause Leber congenital amaurosis and identify a new disease pathway for retinal degeneration. Nature genetics. 2012;44(9):1035-9.

33. Corton M, Nishiguchi KM, Avila-Fernandez A, Nikopoulos K, Riveiro-Alvarez R, Tatu SD, et al. Exome sequencing of index patients with retinal dystrophies as a tool for molecular diagnosis. PloS one. 2013;8(6):e65574.

34. Kaur A. Novel NMNAT1 mutations causing Leber congenital amaurosis identified. Clinical genetics. 2013;83(1):33-4.

35. Jin X, Qu LH, Meng XH, Xu HW, Yin ZQ. Detecting genetic variations in hereditary retinal dystrophies with next-generation sequencing technology. Molecular vision. 2014;20:553-60.

36. Siemiatkowska AM, Schuurs-Hoeijmakers JH, Bosch DG, Boonstra FN, Riemslag FC, Ruiter $\mathrm{M}$, et al. Nonpenetrance of the most frequent autosomal recessive leber congenital amaurosis mutation in NMNAT1. JAMA ophthalmology. 2014;132(8):1002-4. 37. Siemiatkowska AM, van den Born LI, van Genderen MM, Bertelsen M, Zobor D, Rohrschneider K, et al. Novel compound heterozygous NMNAT1 variants associated with Leber congenital amaurosis. Molecular vision. 2014;20:753-9.

38. Deng $Y$, Huang $H$, Wang $Y$, Liu Z, Li N, Chen $Y$, et al. A novel missense NMNAT1 mutation identified in a consanguineous family with Leber congenital amaurosis by targeted next generation sequencing. Gene. 2015;569(1):104-8. 
39. Hedergott $A$, Volk AE, Herkenrath $P$, Thiele H, Fricke J, Altmuller J, et al. Clinical and genetic findings in a family with NMNAT1-associated Leber congenital amaurosis: case report and review of the literature. Graefe's archive for clinical and experimental ophthalmology = Albrecht von Graefes Archiv fur klinische und experimentelle Ophthalmologie. 2015;253(12):2239-46.

40. Jinda W, Taylor TD, Suzuki Y, Thongnoppakhun W, Limwongse $C$, Lertrit $P$, et al. Whole Exome Sequencing in Eight Thai Patients With Leber Congenital Amaurosis Reveals Mutations in the CTNNA1 and CYP4V2 Genes. Investigative ophthalmology \& visual science. 2017;58(4):2413-20.

41. Coppieters F, Ascari G, Dannhausen K, Nikopoulos K, Peelman F, Karlstetter M, et al. Isolated and Syndromic Retinal Dystrophy Caused by Biallelic Mutations in RCBTB1, a Gene Implicated in Ubiquitination. American journal of human genetics. 2016;99(2):47080.

42. Li J, Tang J, Feng Y, Xu M, Chen R, Zou X, et al. Improved Diagnosis of Inherited Retinal Dystrophies by High-Fidelity PCR of ORF15 followed by Next-Generation Sequencing. The Journal of molecular diagnostics : JMD. 2016;18(6):817-24.

43. Tajiguli A, Xu M, Fu Q, Yiming R, Wang K, Li Y, et al. Next-generation sequencingbased molecular diagnosis of 12 inherited retinal disease probands of Uyghur ethnicity. Scientific reports. 2016;6:21384. 
44. Ventura MJ, Wheaton D, Xu M, Birch D, Bowne SJ, Sullivan LS, et al. Diagnosis of a mild peroxisomal phenotype with next-generation sequencing. Molecular genetics and metabolism reports. 2016;9:75-8.

45. Xu M, Eblimit A, Wang J, Li J, Wang F, Zhao L, et al. ADIPOR1 Is Mutated in Syndromic Retinitis Pigmentosa. Human mutation. 2016;37(3):246-9.

46. Soens ZT, Li Y, Zhao L, Eblimit A, Dharmat R, Li Y, et al. Hypomorphic mutations identified in the candidate Leber congenital amaurosis gene CLUAP1. Genetics in medicine : official journal of the American College of Medical Genetics. 2016;18(10):1044-51.

47. Zhao L, Wang F, Wang H, Li Y, Alexander S, Wang K, et al. Next-generation sequencing-based molecular diagnosis of 82 retinitis pigmentosa probands from Northern Ireland. Human genetics. 2015;134(2):217-30.

48. Greenwald SH, Charette JR, Staniszewska M, Shi LY, Brown SD, Stone L, et al. Mouse Models of NMNAT1-Leber Congenital Amaurosis (LCA9) Recapitulate Key Features of the Human Disease. The American journal of pathology. 2016;186(7):192538.

49. Wang J, Zhai Q, Chen Y, Lin E, Gu W, McBurney MW, et al. A local mechanism mediates NAD-dependent protection of axon degeneration. The Journal of cell biology. 2005;170(3):349-55. 
50. Araki T, Sasaki Y, Milbrandt J. Increased nuclear NAD biosynthesis and SIRT1 activation prevent axonal degeneration. Science (New York, NY). 2004;305(5686):1010-3. 51. Adalbert R, Gillingwater TH, Haley JE, Bridge K, Beirowski B, Berek L, et al. A rat model of slow Wallerian degeneration (WIdS) with improved preservation of neuromuscular synapses. The European journal of neuroscience. 2005;21(1):271-7. 52. Conforti L, Fang G, Beirowski B, Wang MS, Sorci L, Asress S, et al. NAD(+) and axon degeneration revisited: Nmnat1 cannot substitute for Wld(S) to delay Wallerian degeneration. Cell death and differentiation. 2007;14(1):116-27.

53. Jia H, Yan T, Feng Y, Zeng C, Shi X, Zhai Q. Identification of a critical site in Wld(s): essential for Nmnat enzyme activity and axon-protective function. Neuroscience letters. 2007;413(1):46-51.

54. Watanabe M, Tsukiyama T, Hatakeyama S. Protection of vincristine-induced neuropathy by WIdS expression and the independence of the activity of Nmnat1. Neuroscience letters. 2007;411(3):228-32.

55. Avery MA, Sheehan AE, Kerr KS, Wang J, Freeman MR. Wld S requires Nmnat1 enzymatic activity and N16-VCP interactions to suppress Wallerian degeneration. The Journal of cell biology. 2009;184(4):501-13.

56. Babetto E, Beirowski B, Janeckova L, Brown R, Gilley J, Thomson D, et al. Targeting NMNAT1 to axons and synapses transforms its neuroprotective potency in vivo. The 
Journal of neuroscience : the official journal of the Society for Neuroscience. 2010;30(40):13291-304.

57. Feng $Y$, Yan T, Zheng J, Ge X, Mu Y, Zhang Y, et al. Overexpression of Wld(S) or Nmnat2 in mauthner cells by single-cell electroporation delays axon degeneration in live zebrafish. Journal of neuroscience research. 2010;88(15):3319-27.

58. Houtkooper RH, Canto C, Wanders RJ, Auwerx J. The secret life of NAD+: an old metabolite controlling new metabolic signaling pathways. Endocrine reviews. 2010;31(2):194-223.

59. Press C, Milbrandt J. Nmnat delays axonal degeneration caused by mitochondrial and oxidative stress. The Journal of neuroscience : the official journal of the Society for Neuroscience. 2008;28(19):4861-71.

60. Yahata N, Yuasa S, Araki T. Nicotinamide mononucleotide adenylyltransferase expression in mitochondrial matrix delays Wallerian degeneration. The Journal of neuroscience : the official journal of the Society for Neuroscience. 2009;29(19):6276-84. 61. Berger F, Lau C, Dahlmann M, Ziegler M. Subcellular compartmentation and differential catalytic properties of the three human nicotinamide mononucleotide adenylyltransferase isoforms. The Journal of biological chemistry. 2005;280(43):3633441.

62. Fainzilber M, Twiss JL. Tracking in the Wlds--the hunting of the SIRT and the luring of the Draper. Neuron. 2006;50(6):819-21. 
63. Gillingwater TH, Wishart TM, Chen PE, Haley JE, Robertson K, MacDonald SH, et

al. The neuroprotective WIdS gene regulates expression of PTTG1 and erythroid differentiation regulator 1 -like gene in mice and human cells. Human molecular genetics. 2006;15(4):625-35.

64. Berger F, Lau C, Ziegler M. Regulation of poly(ADP-ribose) polymerase 1 activity by the phosphorylation state of the nuclear NAD biosynthetic enzyme NMN adenylyl transferase 1. Proceedings of the National Academy of Sciences of the United States of America. 2007;104(10):3765-70.

65. Gilley J, Coleman MP. Endogenous Nmnat2 is an essential survival factor for maintenance of healthy axons. PLoS biology. 2010;8(1):e1000300.

66. Conforti L, Janeckova L, Wagner D, Mazzola F, Cialabrini L, Di Stefano M, et al. Reducing expression of NAD + synthesizing enzyme NMNAT1 does not affect the rate of Wallerian degeneration. The FEBS journal. 2011;278(15):2666-79.

67. Meyer zu Horste G, Miesbach TA, Muller Jl, Fledrich R, Stassart RM, Kieseier BC, et al. The Wlds transgene reduces axon loss in a Charcot-Marie-Tooth disease $1 \mathrm{~A}$ rat model and nicotinamide delays post-traumatic axonal degeneration. Neurobiology of disease. 2011;42(1):1-8.

68. Zhao H, Zhang JY, Yang ZC, Liu M, Gang BZ, Zhao QJ. Nicotinamide mononucleotide adenylyltransferase 1 gene NMNAT1 regulates neuronal dendrite and axon morphogenesis in vitro. Chinese medical journal. 2011;124(20):3373-7. 
69. Antenor-Dorsey JA, O'Malley KL. WIdS but not Nmnat1 protects dopaminergic neurites from MPP+ neurotoxicity. Molecular neurodegeneration. 2012;7:5.

70. Orsomando G, Cialabrini L, Amici A, Mazzola F, Ruggieri S, Conforti L, et al. Simultaneous single-sample determination of NMNAT isozyme activities in mouse tissues. PloS one. 2012;7(12):e53271.

71. Felici R, Lapucci A, Ramazzotti M, Chiarugi A. Insight into molecular and functional properties of NMNAT3 reveals new hints of NAD homeostasis within human mitochondria. PloS one. 2013;8(10):e76938.

72. Song T, Yang L, Kabra N, Chen L, Koomen J, Haura EB, et al. The NAD+ synthesis enzyme nicotinamide mononucleotide adenylyltransferase (NMNAT1) regulates ribosomal RNA transcription. The Journal of biological chemistry. 2013;288(29):2090817.

73. Xu M, Yamada T, Sun Z, Eblimit A, Lopez I, Wang F, et al. Mutations in POMGNT1 cause non-syndromic retinitis pigmentosa. Human molecular genetics. 2016;25(8):147988.

74. Zhang Q, Xu M, Verriotto JD, Li Y, Wang H, Gan L, et al. Next-generation sequencing-based molecular diagnosis of 35 Hispanic retinitis pigmentosa probands.

Scientific reports. 2016;6:32792. 
75. Zhao L, Chen Y, Bajaj AO, Eblimit A, Xu M, Soens ZT, et al. Integrative subcellular proteomic analysis allows accurate prediction of human disease-causing genes. Genome research. 2016;26(5):660-9.

76. Agrawal SA, Burgoyne T, Eblimit A, Bellingham J, Parfitt DA, Lane A, et al. REEP6 deficiency leads to retinal degeneration through disruption of ER homeostasis and protein trafficking. Human molecular genetics. 2017;26(14):2667-77.

77. Chen Y, Zhao L, Wang Y, Cao M, Gelowani V, Xu M, et al. SeqCNV: a novel method for identification of copy number variations in targeted next-generation sequencing data. BMC bioinformatics. 2017;18(1):147.

78. Fu Q, Xu M, Chen X, Sheng X, Yuan Z, Liu Y, et al. CEP78 is mutated in a distinct type of Usher syndrome. Journal of medical genetics. 2017;54(3):190-5.

79. Bramall AN, Wright AF, Jacobson SG, Mclnnes RR. The genomic, biochemical, and cellular responses of the retina in inherited photoreceptor degenerations and prospects for the treatment of these disorders. Annual review of neuroscience. 2010;33:441-72.

80. Soens ZT, Branch J, Wu S, Yuan Z, Li Y, Li H, et al. Leveraging splice-affecting variant predictors and a minigene validation system to identify Mendelian diseasecausing variants among exon-captured variants of uncertain significance. Human mutation. 2017;38(11):1521-33.

81. Sullivan LS, Bowne SJ, Koboldt DC, Cadena EL, Heckenlively JR, Branham KE, et al. A Novel Dominant Mutation in SAG, the Arrestin-1 Gene, Is a Common Cause of 
Retinitis Pigmentosa in Hispanic Families in the Southwestern United States.

Investigative ophthalmology \& visual science. 2017;58(5):2774-84.

82. Xu M, Xie YA, Abouzeid H, Gordon CT, Fiorentino A, Sun Z, et al. Mutations in the Spliceosome Component CWC27 Cause Retinal Degeneration with or without Additional

Developmental Anomalies. American journal of human genetics. 2017;100(4):592-604.

83. Yuan Z, Li B, Xu M, Chang EY, Li H, Yang L, et al. The phenotypic variability of HK1-associated retinal dystrophy. Scientific reports. 2017;7(1):7051.

\section{FIGURE LEGENDS}

Figure 1.

(A) The relative retinal thickness of retinal cell layers at $\mathrm{P}_{7}$ in $\mathrm{WT}$ and $\mathrm{KO}$ mice $(\mathrm{n}=5)$

(B) The relative retinal thickness of retinal cell layers at P14 in WT and KO mice $(n=6)$.

(C) The relative retinal thickness of retinal cell layers at P28 in WT and KO mice $(n=6)$

(D)The ERG a-wave responses at $\mathrm{P}_{2} 8$ in $\mathrm{WT}$ and $\mathrm{KO}$ mice.

(E) The ERG b-wave responses at P28 in WT and $\mathrm{KO}$ mice.

O+I: outer nuclear layer and inner nuclear layer; G, ganglion cell layer. The unit in ERG experiments is $\mu \mathrm{V}$. 
A

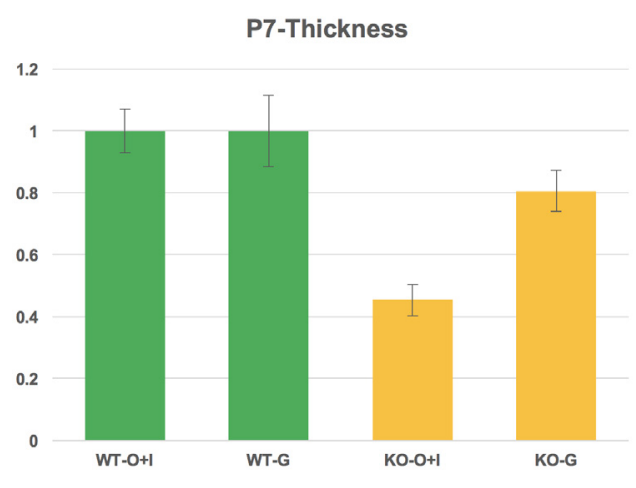

B

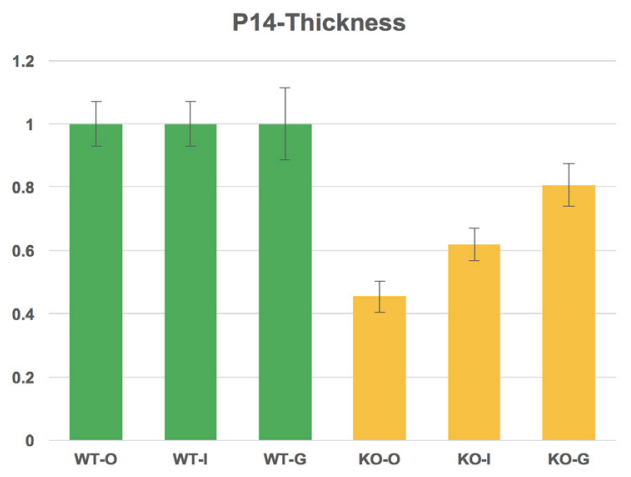

C

P28-Thickness

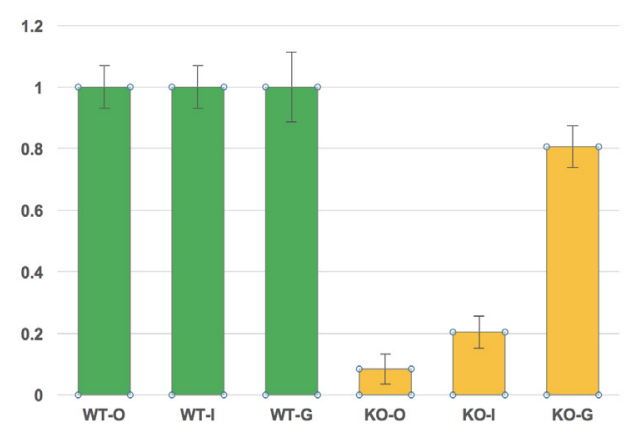

D

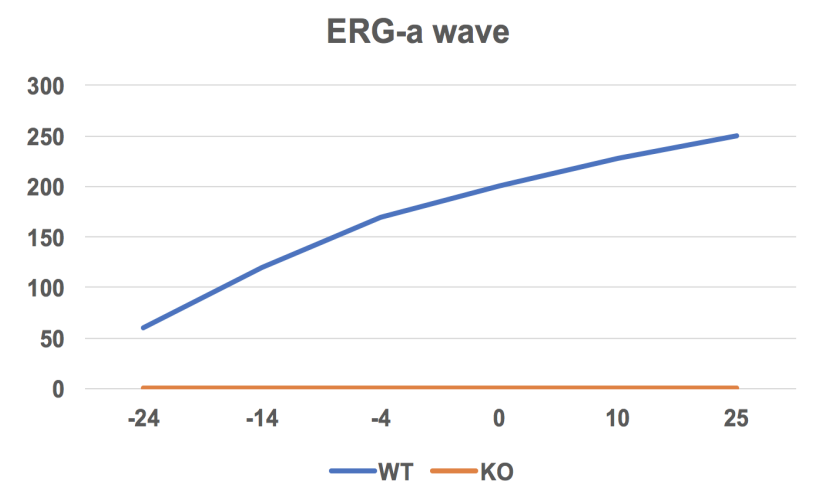

\section{$\mathbf{E}$}

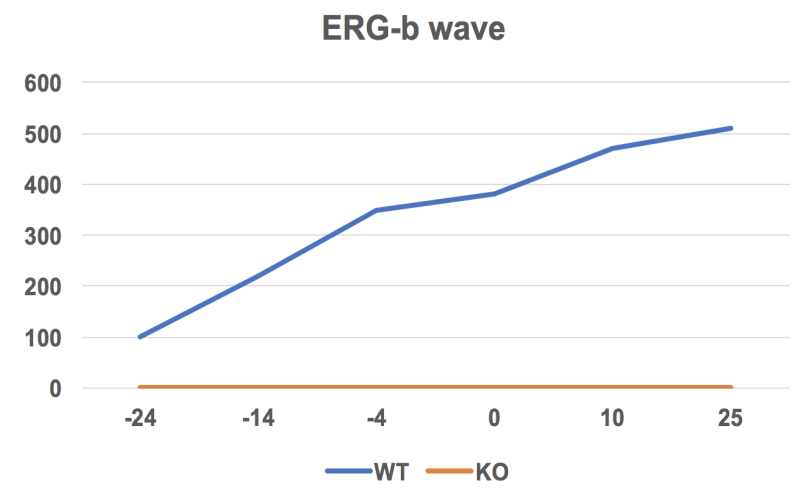

